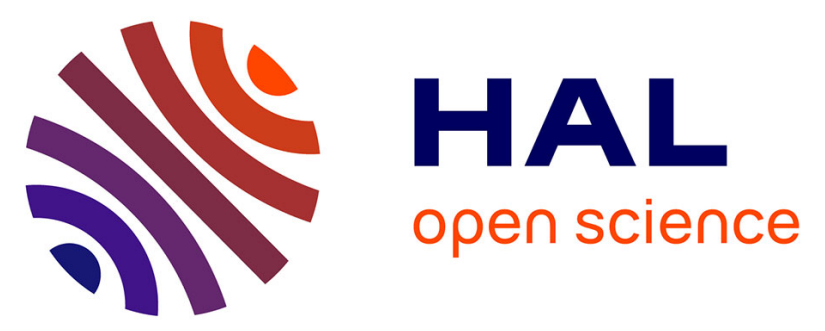

\title{
Impact on survival of the number of lymph nodes removed in patients with node-negative gastric cancer submitted to extended lymph node dissection
}

R. Biffi, E. Botteri, S. Cenciarelli, F. Luca, S. Pozzi, M. Valvo, A. Sonzogni, A. Chiappa, T. Leal Ghezzi, N. Rotmensz, et al.

\section{To cite this version:}

R. Biffi, E. Botteri, S. Cenciarelli, F. Luca, S. Pozzi, et al.. Impact on survival of the number of lymph nodes removed in patients with node-negative gastric cancer submitted to extended lymph node dissection. EJSO - European Journal of Surgical Oncology, 2011, 37 (4), pp.305. 10.1016/j.ejso.2011.01.013 . hal-00677325

\section{HAL Id: hal-00677325 \\ https://hal.science/hal-00677325}

Submitted on 8 Mar 2012

HAL is a multi-disciplinary open access archive for the deposit and dissemination of scientific research documents, whether they are published or not. The documents may come from teaching and research institutions in France or abroad, or from public or private research centers.
L'archive ouverte pluridisciplinaire HAL, est destinée au dépôt et à la diffusion de documents scientifiques de niveau recherche, publiés ou non, émanant des établissements d'enseignement et de recherche français ou étrangers, des laboratoires publics ou privés. 


\section{Accepted Manuscript}

Title: Impact on survival of the number of lymph nodes removed in patients with nodenegative gastric cancer submitted to extended lymph node dissection

Authors: R. Biffi, E. Botteri, S. Cenciarelli, F. Luca, S. Pozzi, M. Valvo, A. Sonzogni, A. Chiappa, T. Leal Ghezzi, N. Rotmensz, V. Bagnardi, B. Andreoni.

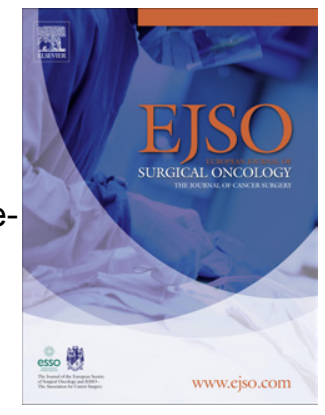

PII:

S0748-7983(11)00015-1

DOI:

10.1016/j.ejso.2011.01.013

Reference: YEJSO 3108

To appear in: European Journal of Surgical Oncology

Received Date: 31 August 2010

Revised Date: 2 January 2011

Accepted Date: 10 January 2011

Please cite this article as: Biffi R, Botteri E, Cenciarelli S, Luca F, Pozzi S, Valvo M, Sonzogni A, Chiappa A, Leal Ghezzi T, Rotmensz N, Bagnardi V, Andreoni. B. Impact on survival of the number of lymph nodes removed in patients with node-negative gastric cancer submitted to extended lymph node dissection, European Journal of Surgical Oncology (2011), doi: 10.1016/j.ejso.2011.01.013

This is a PDF file of an unedited manuscript that has been accepted for publication. As a service to our customers we are providing this early version of the manuscript. The manuscript will undergo copyediting, typesetting, and review of the resulting proof before it is published in its final form. Please note that during the production process errors may be discovered which could affect the content, and all legal disclaimers that apply to the journal pertain. 
Impact on survival of the number of lymph nodes removed in patients with nodenegative gastric cancer submitted to extended lymph node dissection.

BIFFI, R. ${ }^{1}$, BOTTERI, E. ${ }^{2}$, CENCIARELLI, S. ${ }^{1}$, LUCA, F. ${ }^{1}$, POZZI, S. ${ }^{1}$, VALVO, M. ${ }^{1}$, SONZOGNI, A. ${ }^{3}$, CHIAPPA, A. ${ }^{4}$, LEAL GHEZZI, T. ${ }^{1}$, ROTMENSZ, N. ${ }^{2}$, BAGNARDI, V. ${ }^{2,5}$, ANDREONI, B. ${ }^{4}$.

${ }^{1}$ Division of Abdomino-Pelvic Surgery, ${ }^{2}$ Division of Epidemiology and Biostatistics, ${ }^{3}$ Division of Pathology, ${ }^{4}$ Division of General and Laparoscopic Surgery, all at the European Institute of Oncology, Milan, Italy. ${ }^{5}$ Department of Statistics, University of Milan-Bicocca, Milan, Italy.

Corresponding Author:

Roberto Biffi, MD

Director - Division of Abdomino-Pelvic Surgery

European Institute of Oncology

Via Ripamonti 435, I-20141 Milan, Italy

Tel: +39 0257489609 or 9930 (secretariat)

Facsimile:+3902 94379215

e-mail: roberto.biffi@ ieo.it 


\section{ABSTRACT}

Purpose: This study was designed to establish whether the number of lymph nodes removed has an effect on prognosis in patients with node-negative gastric cancer.

Patients and Methods: We retrospectively analyzed data of 114 consecutive patients who underwent gastrectomy and extended lymph node dissection for node-negative adenocarcinoma of the stomach between 2000 and 2005 . Standard survival methods and restricted cubic spline multivariable Cox regression models were applied.

Results: Median age was 63 years and 67 patients out of 114 (59\%) were males. Median number of dissected LNs was 22 (range 2-73). Median follow-up was 76 months. Patients who had $\leq 15$ nodes removed had significantly worse distant disease free survival, disease free survival and overall survival at multivariable analysis than other patients. The results did not change when pT1 and pT2-3 cancer patients were analyzed separately. The risk of distant metastases decreased as the number of dissected lymph nodes increased $(>15)$.

Conclusions: More extended lymph node resection offered survival benefit even in the subgroup of patients with early stage disease. Lymphadenectomy involving more than 15 lymph nodes should be performed for the treatment of node-negative gastric cancer.

Synopsis: The impact on survival of the number of lymph nodes removed in patients with node-negative gastric cancer has not been established. This study suggests that more extended lymph node resection offers protection, as patients who had $\leq 15$ nodes removed had significantly worse disease free survival and overall survival at multivariate analysis than patients in whom $>15$ nodes were removed.

Key words: gastric cancer, gastrectomy, extended lymph node dissection, TNM classification, preoperative chemotherapy. 


\section{INTRODUCTION}

\section{Background}

Despite a declining incidence in the Western world, gastric cancer still is a major malignant disease and the second leading cause of cancer mortality worldwide (1). The prognosis of a locally advanced tumour is generally poor in Western surgical and population-based series, with a 5 -year overall survival of $25 \%$ or less (2), in spite of apparently radical excision of the gastric and nodal components of the disease.

The extent of lymphadenectomy in the treatment of gastric cancer still is a matter of worldwide debate, since the introduction of extended lymphadenectomy (D2) by Japanese surgeons in the 1960s. While Japanese surgeons routinely perform a D2 dissection, the rationale being that the orderly centrifugal pattern of lymphatic tumour dissemination allows for the prediction of the risk of metastasis to specific nodal groups (3), many Western surgeons perform more limited (D1) lymph node dissection, not having found advantages with extensive lymphadenectomy in two large European randomized clinical trials $(4,5)$ and one meta-analysis $(6)$. Current evidence is compatible with no benefit from D2 resection, but also with substantial benefit in a subgroup of patients with advanced N2 disease, or in all patients after a long-term (15-year) follow-up (7). Furthermore, the benefit from $\mathrm{D} 2$ resection is evident only when operative mortality is less than $2 \%$, a result that is achievable only by centres of excellence with a high-volume experience in the resection of gastric cancer (8-10). Previous studies have shown that survival of patients with locally advanced gastric adenocarcinoma is related to the number of regional lymph nodes (LNs) with metastases (11). As the probability of identifying node-positive cancers increases with the number of LNs removed and examined, the UICC-TNM Classification of Malignant Tumours recommends the removal and examination of at least 16 LNs for adequate staging.

\section{Purpose of the study}

Extent of lymphadenectomy could play an important role also in less advanced disease. While prospective randomized studies have shown that the lymph node yield is much greater with D2 than with D1 resection, the effect of the number of surgically removed nodes on survival in node-negative gastric cancers has not been established. 
Specifically, what still is unclear is whether evaluating more than 15 nodes offers any disease-free or overall survival benefit in this clinical setting. This was the aim of the present study, which evaluated the contribution of the number of removed cancer-negative nodes to the long-term outcome of patients with gastric cancer submitted to D2 dissection. 


\section{PATIENTS AND METHODS}

\section{Patient population}

We analyzed data of 100 consecutive patients admitted to the Department of General Surgery of the European Institute of Oncology (IEO) in Milan for adenocarcinoma of the stomach between 2000 and 2005. They all underwent gastrectomy (total or subtotal) and extended lymph node dissection, resulting in node-negative disease. Fourteen additional patients, who were referred to IEO for a second opinion, were taken into consideration; they had undergone the same surgical procedure elsewhere and a comprehensive assessment of their clinical records showed that the pathologic stage of their tumours was the same. Data for this study were extracted from the IEO Tumour Registry (TR), an Institutional database activated in March 2006, with the objective of collecting data on all individuals consulting the IEO, independently of whether they actually received treatment at the Institute or not (12). The inclusion criteria for the present study population were: no previous diagnosis of other cancers, radical resection $(R 0)$, pathologic diagnosis of adenocarcinoma of the stomach, no $L N$ involvement and no synchronous distant metastases (any pT, pNO and M0, according to the UICC-TNM Classification). No age limits were defined. This study was approved by the Scientific Research Committee of IEO.

\section{Diagnosis and staging procedures}

All patients affected by pathologically-proven adenocarcinoma of the stomach were submitted to a preoperative staging work-up in the attempt to perform curative surgery. It included a physical examination, a CT scan of the abdomen and pelvis, a chest X-ray (or Thorax CT scan in selected cases), a liver US scan, a gastric Endoscopic Ultrasound scan (in selected cases), and upper Gl endoscopy and confirmatory biopsies, if they had not already been performed at our Institution. Preoperative PET scan was not routinely used in this clinical series, as at that time it was not available for routine use. Patients were considered eligible for gastrectomy and extended lymph node D2 dissection when they had no evidence of metastatic spread according to preoperative investigations. 


\section{Surgical technique}

First of all, careful intraoperative staging of disease was performed, in order to rule out peritoneal seeding, ovarian involvement, "drop" metastasis in the pelvis, or gross periaortic adenopathy.. The extent of gastrectomy depended on the proximal distance of the tumour from the cardias: total gastrectomy was performed in all patients with cardias involvement and in the presence of antral and/or body tumours, when a 6-cm gross proximal margin could not be obtained.

Lymphadenectomy included excision of all $\mathrm{N} 1$ and most $\mathrm{N} 2$ stations (stations 7, 8, 9 and station 11), according to the classification of the Japanese Research Society for the Study of Gastric Cancer (JRSGC) $(13,14)$. Hepatoduodenal ligament nodes (station 12) were also dissected, limiting the lymphadenectomy to station 12a (left side of the hepatic artery), and leaving parts $b$ and $p$ of the station (right side of the ligament and the part immediately posterior to the portal vein, respectively) undissected. LNs of the surgical specimen were routinely dissected by experienced pathologists with standard techniques. Caudal pancreas was always preserved, according to Maruyama's technique, even when splenectomy was performed, unless direct involvement of the tumour was clinically evident (15).

\section{Statistical methods}

Kruskal-Wallis Test, Chi-square test and Mantel-Haenszel Chi-Square for trends were used to test differences in distributions between patients who had $>15 \mathrm{LNs}$ dissected and those who had $\leq 15$.

Distant disease-free survival (DDFS) was defined as the time free of both tumour recurrence at distant sites and death from any cause. Other primary tumours were considered as censoring events. Disease-free survival (DFS) was calculated from the date of surgery to any loco-regional or distant recurrence, other primary tumour and death from any cause. Overall survival (OS) was calculated from the date of surgery to death from any cause. In the absence of any of the above-mentioned events, survivals were censored at last follow-up visit. Survival curves were estimated using the Kaplan-Meier method and compared by the Log-rank test. The prognostic impact of the number of extracted LNs on 
survival was evaluated using the multivariate Cox proportional hazard regression model and expressed as hazard ratio $(\mathrm{HR})$ with $95 \%$ Confidence Intervals $(\mathrm{Cl})$.

The functional form of the relationship between DDFS and the number of dissected LNs analysed as a continuous variable was evaluated fitting a restricted cubic spline multivariable Cox regression model (16). Three knots were placed at quartile values (17, 22 and 29 LNs). Other numbers and positions of knots were examined, and the curves were similar. The model was adjusted for $\mathrm{pT}$, neoadjuvant treatment and place of surgery.

All analyses were carried out with the SAS software (SAS Institute, Cary, NC) and the R software (The R Development Core Team 2004; Free Software Foundation, Boston, MA). All tests were two-sided. 


\section{RESULTS}

\section{Patient characteristics}

Sixty-seven patients out of 114 (58.8\%) were males. Median age was 63 years (range 31-87). Median number of dissected LNs was 22 (range 2-73). One hundred patients $(87.7 \%)$ underwent surgery at the IEO, 14 at other Institutes. Table 1 shows patient and tumour characteristics, stratified by number of dissected LN ( $\leq 15$ LNs versus $>15$ LNs). Twenty-four patients had $\leq 15$ LNs removed, 90 patients had $>15$ LNs harvested ( 45 of them $>25$ lymph nodes). The only significant difference between the two groups was the number of patients who received neoadjuvant chemotherapy: it was significantly higher in the limited lymphadenectomy group ( $P=0.03)$, as expected.

\section{Survival findings}

Median follow-up was 76 months (range 5-129). No patients had a local or regional recurrence, 8 had distant metastases and 11 experienced a second primary cancer at a site other than the stomach. Overall, 9 patients died.

At the univariate survival analysis (Table 2), pT and the number of dissected LNs were found to be associated with DDFS, while the latter was the only statistically significant variable associated with OS.

Figure 1 shows DDFS by number of dissected LNs. Patients with extracted LNs $\leq 15$ had a worse prognosis than other patients: adjusted HR 8.1 (95\% C.I. 2.5-25.7). This result remained statistically significant even after stratifying for $\mathrm{pT}$ (data not shown). The number of dissected nodes had a significant impact also on DFS: adjusted HR of LNs $\leq 15$ versus LNs > 15 was 3.1 (95\% C.I. 1.3-7.6).

Figure 2 shows $\mathrm{OS}$ with stratification by number of dissected LN. Once again, patients with a lower number of nodes had a worse prognosis than patients with a number of nodes exceeding 15 , even after stratifying for $\mathrm{pT}$. Multivariable analysis was not performed in the analysis of OS due to the low number of deaths. DDFS, DFS and OS were significantly associated with the number of dissected LNs even after the exclusion of patients receiving neoadjuvant chemotherapy and patients not operated at IEO ( $\mathrm{N}=87)$. pT-adjusted HRs of LNs $\leq 15$ versus LNs > 15 were 8.4 (95\% C.I. 1.8-38.2) and 3.9 (95\% C.I. 1.2-12.2) for 
DDFS and DFS, respectively. Univariate analysis of OS showed that patients with extracted LNs $\leq 15$ had a worse prognosis than other patients (Log-rank $\mathrm{P}<0.001)$.

Figure 3 shows the DDFS risk by number of LNs analyzed as a continuous variable. Fifteen $L N s$ were chosen as reference $(H R=1)$. The risk of the event was inversely proportional to the number of dissected LNs, even over 15 LNs, up to about 20 LNs; thereafter it slightly increased as the number of dissected LNs increased.. 


\section{DISCUSSION}

Our study was primarily aimed at answering the question whether the number of surgically removed cancer-negative nodes has an effect on distant disease-free (DDFS) and overall survival (OS) in patients with any $\mathrm{pT}$, pNO TNM-staged gastric cancer, who underwent gastrectomy with extended (D2) lymphadenectomy. The results obtained indicate that patients who have > surgically removed 15 LNs have a statistically significant survival advantage, both in terms of DDFS and OS. Moreover, the evaluation of DDFS risk by number of harvested LNs - analyzed as a continuous variable - suggested that the risk of events was inversely proportional to the number of dissected LNs up to about 20 LNs. Interestingly, the results persisted even when pT1 ("early gastric cancer") and pT2-3 cancers (locally advanced) were considered separately, thus indicating the need to remove at least 15 nodes also in patients with early stage disease.

\section{Extent of lymphadenectomy in the treatment of locally advanced and early gastric cancer. Its role in pNO disease.}

The extent of lymphadenectomy in the treatment of gastric cancer is still a matter of debate. The first large multicentre randomized study that compared D1 and D2 dissection was conducted in the Netherlands by the Dutch Gastric Cancer Group (4). A total of 711 patients underwent a curative resection (380 in the D1 group and 331 in the D2 group). Morbidity (25 vs. $43 \%$ ) and mortality (4 vs. $10 \%$ ) were higher following D2 dissection. Fiveyear survival rates were similar in the two groups: $45 \%$ for the D1 group and $47 \%$ for the D2 group. Improved survival was seen in patients with N2 cancer who underwent extended lymph node dissection, but unfortunately it remains difficult to correctly identify patients with N2 disease in preoperative or intraoperative settings. Moreover, as the authors identified splenectomy and pancreatectomy as contributing risk factors for increased morbidity and mortality, they concluded that extended lymph node dissections may be beneficial if morbidity and mortality can be avoided (4). In the most recent update, after 15 years of follow-up, D2 lymphadenectomy was associated with lower locoregional recurrence and tumour-related death rates than D1 surgery (7). Because a safer, spleenpreserving D2 resection technique is available in many centres, authors reached the conclusion that D2 lymphadenectomy is the recommended surgical approach for patients 
with resectable disease. D2 gastrectomy is a safe treatment for gastric cancer in Western patients, at least when it is performed at experienced centres $(9,10)$; moreover, gastric cancer resection should probably be added to the growing list of procedures that are safer when they are performed at high-volume institutions (17). A second large randomized multicentre trial comparing D1 with D2 dissection was conducted by the British Medical Research Council (MRC) (5). Four hundred patients were randomly assigned to treatment (200 to D1 and 200 to D2). The results showed that the D2 group had greater postoperative hospital mortality (13 vs. $6.5 \% ; p=0.04$ ) and higher overall postoperative morbidity ( $46 \%$ vs. $28 \% ; p<0.001$ ). The five-year survival rates were $35 \%$ for D1 resection and $33 \%$ for $D 2$ resection. The authors concluded that $D 2$ resection offered no survival advantage over D1 surgery. A more recent single-centre randomized study in Taiwan $(18,19)$, where 110 patients were randomly assigned to D1 surgery and 111 patients to D3 surgery, demonstrated a survival benefit from extended lymphadenectomy. The morbidity rate was higher after D3 than after D1 resection (17.1 vs. $7.3 \%)$. The overall five-year survival was significantly higher in patients in the D3 group than in the D1 group (59.5 vs. $53.6 \% ; p=0.041$ ). A recent meta-analysis (6) reviewing 14 randomized clinical trials (3,432 patients overall), published in 2009 before the acquisition of the 15year results of the Dutch Trial, confirmed that operative mortality and postoperative morbidity were higher in the D2 group than in the D1 group, and the three- and five-year survival rates were not statistically different.

The Japanese Research Society for the Study of Gastric Cancer (JRSGC) strongly recommends extended lymphadenectomy, although it is still unclear, in terms of high level scientific evidence, whether this procedure improves survival or merely refines staging (20, 21). It is well known that overall survival rates after radical surgical treatment for gastric cancer at Western and Japanese institutions differ substantially. When new lymph node metastases are identified as a consequence of more extended lymphadenectomy and/or more accurate pathologic techniques, nodal staging determines a stage migration of the disease (22). This is a possible explanation of the frequent underestimation of tumour stage in Western series, due to incomplete removal of the LNs necessary for accurate staging. This could partly explain also our findings. We were not able to ascertain whether the difference in the number of lymph nodes found is related to differences in surgical technique or in the quality of histopathological dissection; as a matter of fact, 14 patients were operated on elsewhere and strict adherence to surgical rules of D2 dissection could not be verified. However, in our study DDFS (Fig.1) was adjusted also by surgical centre, 
together with pT stage and preoperative chemotherapy occurrence. From the U.S. National Cancer Data Base Report of 2000 , we know that only $18 \%$ of U.S. patients have $\geq 15 \mathrm{LNs}$ analyzed (23). It is unlikely that selective lymphadenectomy, based upon the gross appearance of LNs, is feasible or appropriate, as $30 \%$ of LN metastases occur in nodes less than $3 \mathrm{~mm}$ in diameter (24) and surgeons are probably able to correctly diagnose metastatic involvement by macroscopic appearance in only $20 \%$ of patients (25). Intraoperative assessment of frozen lymph node sections seems practically unfeasible and largely invalidated by the occurrence of the "skip metastasis" phenomena, as $11 \%$ of patients with negative perigastric nodes show metastatic deposits in more distant nodes, even in pT1 tumours (26).

This adds further points of discussion related to the issue of lymph node dissection in T1 tumours (adenocarcinoma confined to submucosa, EGC: Early Gastric Cancer). The incidence of early gastric cancer has recently increased as advances in diagnostic techniques have made it possible to detect small lesions at an early stage. It was reported that radical lymph node dissection should be limited in patients with EGC, because extended lymph node dissection in these patients offers modest survival benefits $(26,27$, 28). Consequently, new treatment modalities with minimally invasive techniques, such as endoscopic resection, laparoscopic gastrectomy, and robotic surgery, are becoming more frequent in EGC patients. These minimally invasive techniques are focused on enhanced recovery after surgery (ERAS) and improving quality of life, as the survival rates of EGC patients are high $(29,30,31,32)$. A very recent paper (33) assessed the feasibility of radical distal gastrectomy with a mini-laparotomic approach in EGC patients in terms of long-term survival. A mean of approximately $30 \mathrm{LNs}$ were harvested, and no difference in terms of DFS and OS arose from the comparison with a matched series of patients undergoing conventional surgery with a laparotomic approach through a long midline incision. As in our study, no locoregional recurrence to the regional LNs or carcinomatosis peritonei occurred.

Another recent paper (34) assessed oncological outcomes following laparoscopyassisted versus open gastrectomy in patients with lymph node-positive EGC. Mean number of retrieved LNs did not differ between the two groups. During a median follow-up of 35 months, 14 patients (8.6\%) developed recurrence after open surgery, compared with 4 patients $(9.5 \%)$ after laparoscopy procedure. Overall 5 -year disease-free survival was $89.9 \%$ and $89.7 \%$ respectively. Lymph node metastatic status was the only independent 
prognostic factor for disease-free survival. These data reinforce the assumption that an adequate number of LNs must be harvested, independently of the technique adopted.

Findings obtained by another Italian group (Italian Research Group for Gastric Cancer) were somewhat different. This Group collected and analyzed the clinical and pathological characteristics of 301 lymph node-negative advanced gastric carcinoma patients in a multicentre retrospective study on gastrectomy and D2 lymphadenectomy. The factors associated with better disease-free survival at univariate analysis were age $<60$, T2 tumours, distal location, intestinal histotype, and number of retrieved nodes $>25$, whereas in our study disease-free and overall survival were similar in patients having 1625 or $>25$ nodes removed. In this study depth of infiltration and histotype were the only 2 independent predictors of 5-year recurrence-free survival at multivariate analysis (35).

\section{Future perspectives}

Worthy of a final comment is the potential value of sentinel node technique in the identification of the nodes to be removed. A recent study compared lymphatic mapping in early gastric cancer with indocyanin green (IG) and infrared ray electronic endoscopy (IREE) to IG alone (36). The sentinel node identification rate and sensitivity for IREE versus ICG alone were 99.5 and $85.8 \%$ versus 97.0 and $48.4 \%$, respectively. The Authors concluded that dissection of the lymphatic basin, based on IREE, is a safe method of nodal dissection in patients with T1 or limited T2 tumours. These interesting findings need confirmation by larger well-designed studies.

\section{Limitations of this study}

Our study suffers from some limitations. The main limitation is that it was a retrospective study. notwithstanding the added value provided by the accurate methodology used for the statistical analyses. Moreover, the low number of patients with a very large number of LNs removed (i.e. only 8 patients had more than 40 dissected LNs) may have led to unreliable risk estimates for that group of patients. Sampling error is a likely explanation for the slight increase in the risk of recurrence when many LNs were removed, as shown in Fig.3. 
Thirteen patients received neoadjuvant chemotherapy; this is a potential confounding factor that could influence the pathology assessment of lymph node status, as well as patient survival. As shown in Table 1, preoperative neoadjuvant treatment had an impact on the number of harvested lymph nodes, which was significantly lower. Nevertheless, survival curves were adjusted in our study also for this variable, and the protective effect of the number of removed lymph nodes on survival was maintained (Fig. 1).

Finally, we did not stratify the study population in terms of histological type (intestinal vs diffuse/mixed adenocarcinoma, according to Lauren's classification). However, we analyzed tumor grading (1 to 4 ) and did not find significant differences in its distribution in the groups (Table 1).

\section{Conclusion}

In conclusion, more extended lymph node resection resulted in survival benefit, both in terms of DDFS and OS, for patients suffering from node-negative gastric cancer; moreover, evaluation of DDFS risk by number of harvested LNs demonstrated that the risk of events is inversely proportional to the number of dissected LNs, up to 20 . Interestingly, the results did not change when pT1 ("early gastric cancer") and pT2-3 cancers (locally advanced) were analyzed separately, suggesting the need to remove at least 15 nodes even in patients with early stage disease.

\section{Acknowledgements}

The authors would like to thank Elena Albertazzi, Marina Francesca Alfieri, Barbara Bazolli, Nadia Burzoni, Marco Martinetti, Laura Manghi and Bruno Montanari for their precious contribution to data entry and quality control of the IEO Tumour Registry data. 


\section{REFERENCES}

1. Forman D, Burley VJ. Gastric cancer: global pattern of the disease and an overview of environmental risk factors. Best Pract Res Clin Gastroenterol 2006; 20: 633-49.

2. Jemal A, Siegel R, Ward E, Murray T, Xu J, Smigal C et al. Cancer statistics, 2006. CA Cancer J Clin 2006; 56: 106-30.

3. Mine M, Majima S, Harada M, Etani S. End results of gastrectomy for gastric cancer: effect of extensive lymph node dissection. Surgery 1970; 68: 753-8.

4. Hartgrink $\mathrm{HH}$, van de Velde CJ, Putter H, Bonenkamp JJ, Klein Kranenbarg E, Songun I et al. Extended lymph node dissection for gastric cancer: who may benefit? Final results of the randomized Dutch gastric cancer group trial. $J$ Clin Oncol 2004;22:2069-77.

5. Cuschieri A, Weeden S, Fielding J, Bancewicz J, Craven J, Joypaul V et al. Patient survival after D1 and D2 resections for gastric cancer: long-term results of the MRC randomized surgical trial. Surgical Co-operative Group. Br J Cancer 1999;79:152230.

6. Yang SH, Zhang YC, Yang KH, Li YP, He XD, Tian JH et al. An evidence-based medicine review of lymphadenectomy extent for gastric cancer. Am J Surg 2009;197:246-51.

7. Songun I, Putter H, Meershoek-Klein Kranenbarg E, Sasako M, van de Velde C. Surgical treatment of gastric cancer: 15-year follow-up results of the randomised nationwide Dutch D1 D2 trial. Lancet Oncology 2010; 11: 439-49.

8. Kodera E, Fujiwara M, Ito Y, Ohashi N, Nakayama G, Koike M, Nakao A.: Radical surgery for gastric carcinoma: it is not an issue of whether to perform D1 or D2. Dissect as many lymph nodes as possible and you will be rewarded. Acta Chir Belg. 2009; 109: 27-35.

9. Biffi R, Chiappa A, Luca F, Pozzi S, Lo Faso F, Cenciarelli S, Andreoni B. Extended lymph node dissection without routine spleno-pancreatectomy for treatment of gastric cancer: low morbidity and mortality rates in a single centre series of 250 patients. J Surg Oncol. 2006;93:394-400.

10. Degiuli M, Sasako M, Calgaro M, Garino M, Rebecchi F, Mineccia M, Scaglione D, Andreone D, Ponti A, Calvo F. Morbidity and mortality after D1 and D2 gastrectomy for cancer: interim analysis of the Italian Gastric Cancer Study Group (IGCSG) randomised surgical trial. Eur J Surg Oncol. 2004;30:303-308. 
11. Kodera $\mathrm{Y}$, Yamamura $\mathrm{Y}$, Shimizu $\mathrm{Y}$, et al.: The number of metastatic lymph nodes: A promising prognostic determinant for gastric carcinoma in the latest edition of the TNM classification. J Am Coll Surg 1998;187:597-603.

12. Botteri E, lodice $S$, Maisonneuve $P$ et al. Case mix at the European Institute of Oncology: first report of the Tumour Registry, years 2000-2002. Ecancermedicalscience. 2009 doi: 10.3332/ecancer.2009.149

13.Japanese Research Society for Gastric Cancer. Japanese classification of gastric carcinoma. First English Edition. Tokio: Kanehara \& Co. Ltd; 1995.

14.Japanese Gastric Cancer Association. Japanese Classification of Gastric Carcinoma-2nd English Edition- Gastric Cance. 1998;1:10-24.

15. Maruyama K, Sasako M, Kinoshita T, et al.: Pancreas preserving total gastrectomy for proximal gastric cancer. World J Surg 1995;19:532-6.

16. Durrleman S, Simon R. Flexible regression models with cubic splines. Stat Med 1989; 8: 551-61.

17. Sierra A, Regueira FM, Hernández-Lizoáin JL, Pardo F, Martínez-Gonzalez MA, ACienfuegos $\mathrm{J}$. Role of the extended lymphadenectomy in gastric cancer surgery: experience in a single institution. Ann Surg Oncol. 2003;10:219-26.

18. Wu CW, Hsiung CA, Lo SS, Hsieh MC, Shia LT, Whang-Peng J. Randomized clinical trial of morbidity after D1 and D3 surgery for gastric cancer. Br J Surg 2004;91:283-7.

19. Wu CW, Hsiung CA, Lo SS, Hsieh MC, Chen JH, Li AF, et al. Nodal dissection for patients with gastric cancer: a randomised controlled trial. Lancet Oncol 2006;7:309-15.

20. Bunt AMG, Hermans J, Smit VTHM, van de Velde CJH, Fleuren GJ, Bruijn JA. Surgical/Pathologic stage migration confounds comparisons of gastric cancer survival rates between Japan and western countries. J Clin Oncol. 1995;13:19-25.

21. Yoshikawa T, Sasako M, Sano T, Nashimoto A, Kurita A, Tsujinaka T, Tanigawa N, Yamamoto $S$. Stage migration caused by D2 dissection with para-aortic lymphadenectomy for gastric cancer from the results of a prospective randomized trial. Br J Surg. 2006; 93:1526-9.

22. Wu CW, Hsiung CA, Lo SS, Hsieh MC, Chen JH, Li AF, Lui WY, Whang-Peng J. Stage migration influences on stage specific survival comparison between D1 and D3 gastric cancer surgeries. Eur J Surg Oncol 2005; 31:153-7. 
23. Hundahl SA, Phillips JL, Menck HR. The National Cancer Data Base Report on poor survival of U.S. gastric carcinoma patients treated with gastrectomy: Fifth Edition American Joint Committee on Cancer staging, proximal disease, and the "different disease" hypothesis. Cancer 2000; 88:921-32.

24. Keller E, Stutzer H, Heitmann K, et al.: Lymph node staging in 872 patients with carcinoma of the stomach and the presumed benefit of lymphadenectomy. J Am Coll Surg 1994;178: 38-46.

25. Okamura T, Tsujitani S, Korenaga D, et al.: Lymphadenectomy for cure in patients with early gastric cancer and lymph node metastasis. Am J Surg 1988;155:476480.

26. Yoshikawa T, Tsuburaya A, Kobayashi O, Sairenji M, Motohashi H, Noguchi Y. Is D2 lymph node dissection necessary for early gastric cancer? Ann Surg Oncol. 2002;9:401-5.

27. Kasakura Y, Fujii M, Mochizuki F, Asaki H, Kobayashi M. Gastrectomy with D2 lymph node dissection in gastric cancer: a retrospective study at a single institution. Int Surg.2001;86:50-6.

28. Nitti D, Marchet A, Mammano E, Ambrosi A, Belluco C, Mencarelli R, Maino M, Marconato G, Farinati F, Lise M. Extended lymphadenectomy (D2) in patients with early gastric cancer. Eur J Surg Oncol. 2005;31:875-81.

29. Kitano S, Shiraishi N, Kakisako K, Yasuda K, Inomata M, Adachi Y. Laparoscopyassisted Billroth-I gastrectomy (LADG) for cancer: our 10 years' experience. Surg Laparosc Endosc Percutan Tech 2002;12: 204-7.

30. Soetikno RM, Gotoda T, Nakanishi Y, Soehendra N. Endoscopic mucosal resection. Gastrointest Endosc 2003; 57:567-79.

31. Song J, Oh SJ, Kang WH, Hyung WJ, Choi SH, Noh SH. Robot-assisted gastrectomy with lymph node dissection for gastric cancer: lessons learned from an initial 100 consecutive procedures. Ann Surg. 2009;249: 927-32.

32. Kehlet H, Dahl JB. Anaesthesia, surgery, and challenges in postoperative recovery. Lancet. 2003;362:1921-8.

33. Jung $\mathrm{H}$, Jeon $\mathrm{HM}$, Lee $\mathrm{HH}$, Song $\mathrm{KY}$, Park $\mathrm{CH}$. The long-term results of distal gastrectomy by mini-laparotomy in Early Gastric Cancer patients. J Gastrointest Surg. 2010 Jun 30. [Epub ahead of print] 
34. An JY, Heo GU, Cheong JH, Hyung WJ, Choi SH, Noh SH.Assessment of open versus laparoscopy-assisted gastrectomy in lymph node-positive early gastric cancer: a retrospective cohort analysis. J Surg Oncol. 2010 Jul 1;102(1):77-81.

35. Baiocchi GL, Tiberio GA, Minicozzi AM, Morgagni P, Marrelli D, Bruno L, Rosa F, Marchet A, Coniglio A, Saragoni L, Veltri M, Pacelli F, Roviello F, Nitti D, Giulini SM, De Manzoni G. A multicentric Western analysis of prognostic factors in advanced, node-negative gastric cancer patients. Ann Surg 2010 Jul; 252( 1):70-3.

36. Kelder W, Nimura H, Takahashi N, Mitsumori N, van Dam GM, Yanaga K. Sentinel node mapping with indocyanine green (ICG) and infrared ray detection in early gastric cancer: an accurate method that enables a limited lymphadenectomy. Eur $\mathrm{J}$ Surg Oncol. 2010 Jun;36: 552-8. Epub 2010 May 7. 


\section{ACCEPTED MANUSCRIPT}

Table 1: Patient characteristics, with stratification for number of dissected lymph nodes

\begin{tabular}{|c|c|c|c|c|c|}
\hline & & $\begin{array}{c}\text { All } \\
\text { patients } \\
\text { No. } 114\end{array}$ & $\begin{array}{c}\text { Dissected lymph } \\
\text { nodes } \leq 15 \\
\text { No. } 24\end{array}$ & $\begin{array}{c}\text { Dissected lymph } \\
\text { nodes }>15 \\
\text { No. } 90\end{array}$ & $\begin{array}{l}\mathrm{X}^{2} \text { test } \\
\text { P-value }\end{array}$ \\
\hline Age & $\begin{array}{l}\text { Median } \\
\text { (Range) }\end{array}$ & $63(31-87)$ & $62(39-78)$ & $63(31-87)$ & $0.88^{\mathrm{b}}$ \\
\hline \multirow{3}{*}{ Age } & $<50$ & 17 & 2 & 15 & \multirow{3}{*}{0.45} \\
\hline & $50-64$ & 50 & 13 & 37 & \\
\hline & $\geq 65$ & 47 & 9 & 38 & \\
\hline \multirow{2}{*}{ Sex } & $M$ & 67 & 18 & 49 & \multirow{2}{*}{0.10} \\
\hline & $\mathrm{F}$ & 47 & 6 & 41 & \\
\hline \multirow{2}{*}{$\begin{array}{c}\text { Type of } \\
\text { Adenocarcinoma }\end{array}$} & Intestinal & 50 & 10 & 40 & \multirow{2}{*}{0.80} \\
\hline & Diffuse & 64 & 14 & 50 & \\
\hline \multirow{4}{*}{ pT } & 1 & 52 & 12 & 40 & \multirow{4}{*}{$0.25^{\mathrm{c}}$} \\
\hline & 2 & 46 & 9 & 37 & \\
\hline & 3 & 13 & 1 & 12 & \\
\hline & $x$ & 3 & 2 & 1 & \\
\hline \multirow{5}{*}{ Grading $^{a}$} & 1 & 16 & 6 & 10 & \multirow{5}{*}{$0.79^{d}$} \\
\hline & 2 & 37 & 5 & 32 & \\
\hline & 3 & 36 & 5 & 31 & \\
\hline & 4 & 6 & 2 & 4 & \\
\hline & NA & 13 & 6 & 7 & \\
\hline \multirow{2}{*}{$\begin{array}{l}\text { Neoadjuvant } \\
\text { treatment }\end{array}$} & Yes & 13 & 6 & 7 & \multirow{2}{*}{0.03} \\
\hline & No & 101 & 18 & 83 & \\
\hline
\end{tabular}

NA: Not Applicable. ${ }^{a}$ Information is missing for some patients; ${ }^{b}$ Kruskal-Wallis Test ${ }^{c} p T X$ excluded. P-value from the Mantel-Haenszel Chi-Square for trend; ${ }^{\mathrm{d}} \mathrm{G} 1 / \mathrm{G} 2$ vs. G3/G4 
Table 2: Survival by clinico-pathological characteristics

\begin{tabular}{|c|c|c|c|c|c|c|}
\hline & & At risk & $\begin{array}{c}\text { DDFS } \\
\text { Events (\%) }\end{array}$ & P-value & $\begin{array}{c}\text { OS } \\
\text { Events (\%) } \\
\end{array}$ & P-value \\
\hline All patients & & 114 & $14(12)$ & & $9(8)$ & \\
\hline \multirow{3}{*}{ Age } & $<50$ & 17 & 2 (12) & & $0(0)$ & \multirow{3}{*}{0.38} \\
\hline & $50-64$ & 50 & $5(10)$ & 0.68 & $4(8)$ & \\
\hline & $\geq 65$ & 47 & 7 (15) & & $5(11)$ & \\
\hline \multirow{2}{*}{ Sex } & $M$ & 67 & $9(13)$ & \multirow{2}{*}{0.59} & $6(9)$ & \multirow{2}{*}{0.63} \\
\hline & $\mathrm{F}$ & 47 & $5(11)$ & & $3(6)$ & \\
\hline \multirow{2}{*}{$\begin{array}{c}\text { Type of } \\
\text { Adenocarcinoma }\end{array}$} & Intestinal & 50 & $7(14)$ & \multirow{2}{*}{0.64} & $5(10)$ & \multirow{2}{*}{0.52} \\
\hline & Diffuse & 64 & $7(11)$ & & $4(6)$ & \\
\hline \multirow{3}{*}{ pT } & 1 & 52 & $3(6)$ & \multirow{3}{*}{$\begin{array}{l}0.08 \\
0.03^{\mathrm{a}}\end{array}$} & $3(6)$ & \multirow{3}{*}{$\begin{array}{l}0.64 \\
0.35^{\mathrm{a}}\end{array}$} \\
\hline & 2 & 46 & $8(17)$ & & $5(11)$ & \\
\hline & 3 & 13 & $3(23)$ & & $1(8)$ & \\
\hline \multirow{3}{*}{$\begin{array}{c}\text { Number of } \\
\text { dissected lymph } \\
\text { nodes }\end{array}$} & $2-15$ & 24 & $8(33)$ & & 7 (29) & \multirow{3}{*}{$<0.01$} \\
\hline & $16-25$ & 45 & $3(7)$ & $<0.01$ & $1(2)$ & \\
\hline & $>25$ & 45 & $3(7)$ & & $1(2)$ & \\
\hline \multirow{2}{*}{ Grading } & $1-2$ & 53 & $5(14)$ & 51 & $4(8)$ & \multirow{2}{*}{0.98} \\
\hline & $3-4$ & 42 & $6(17)$ & & $3(7)$ & \\
\hline \multirow{2}{*}{$\begin{array}{l}\text { Neoadjuvant } \\
\text { treatment }\end{array}$} & Yes & 13 & $2(15)$ & \multirow{2}{*}{0.76} & $2(15)$ & \multirow{2}{*}{0.32} \\
\hline & No & 101 & $12(12)$ & & $7(7)$ & \\
\hline
\end{tabular}

DDFS: Distant Disease Free Survival; OS: Overall Survival; P-value from the Log-rank test. ${ }^{a}$ pT1 vs pT2/3 
Figure 1: Distant disease free survival with stratification for number of dissected lymph nodes

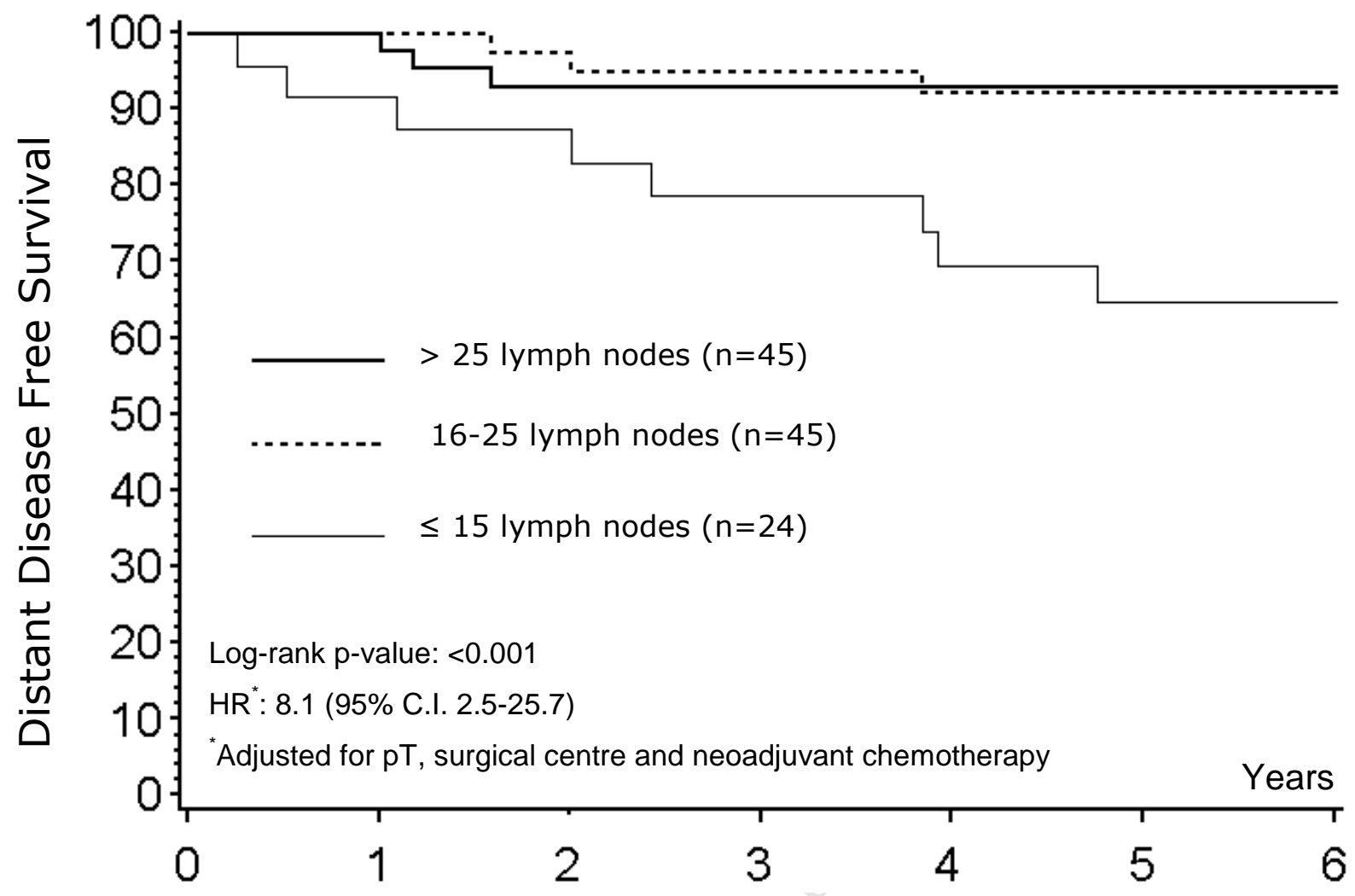


Figure 2: Overall survival with stratification for number of dissected lymph nodes

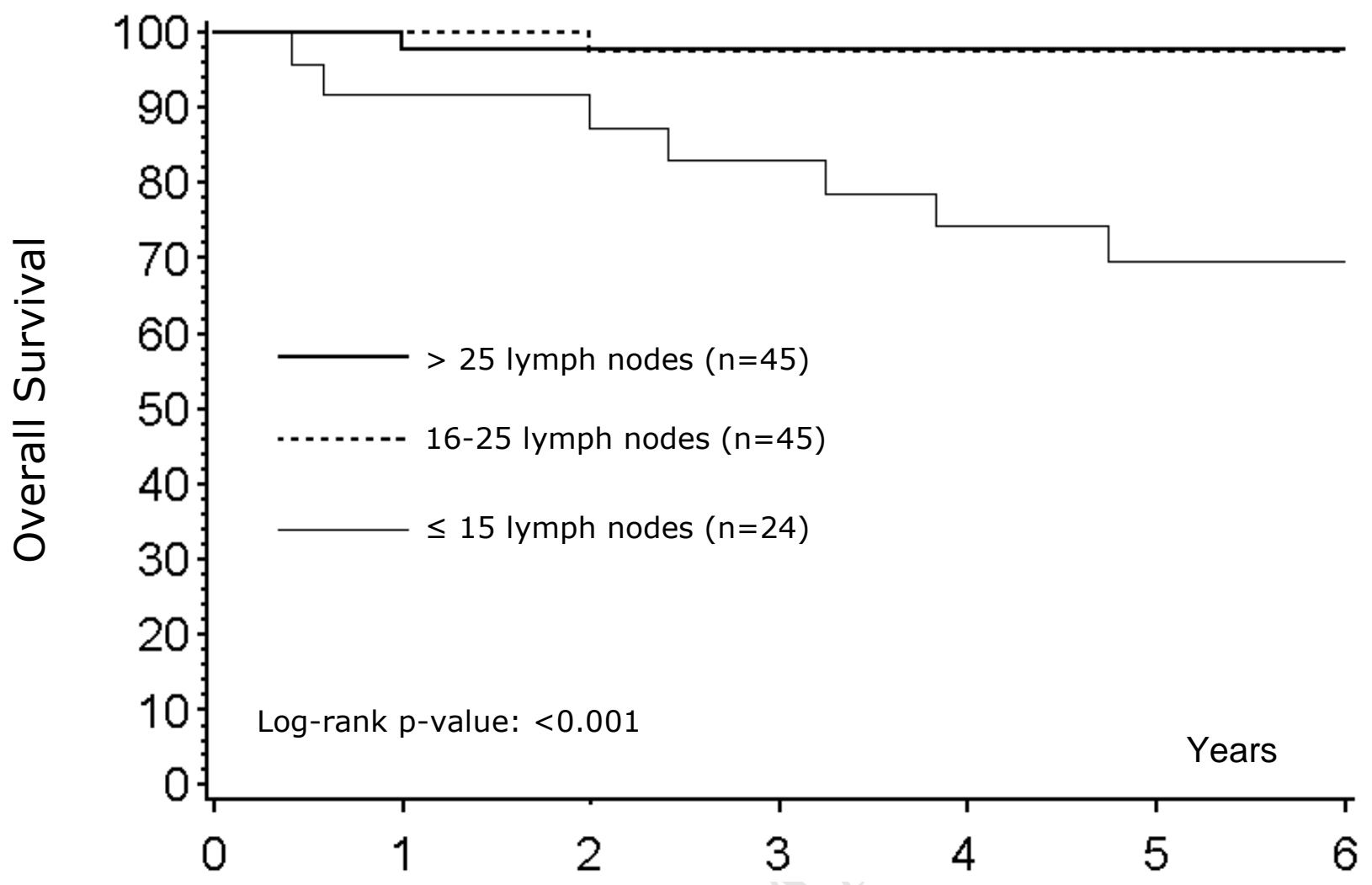


Figure 3: Distant disease free survival according to number of dissected lymph nodes

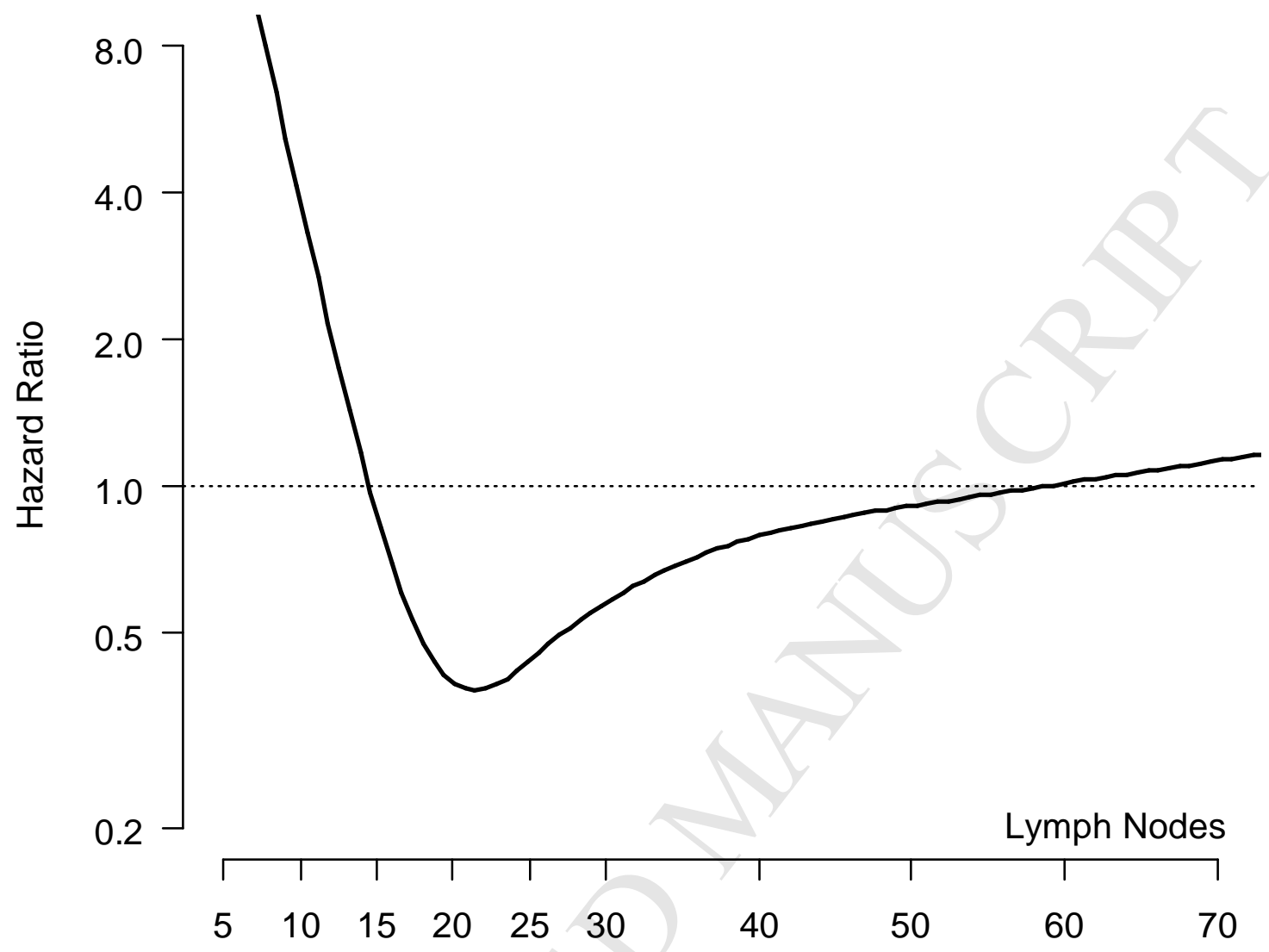

HR is plotted on a log scale. HR was adjusted for pT, surgical centre and neoadjuvant chemotherapy. 15 lymph nodes is the reference $(\mathrm{HR}=1)$. 